\title{
A trypsin-like protease with apparent dual function in early Lepeophtheirus salmonis (Krøyer) development Rasmus Skern-Mauritzen ${ }^{*}$, Petter Frost ${ }^{1,2}$, Sussie Dalvin ${ }^{1}$, Bjørn Olav Kvamme ${ }^{3}$, Ingunn Sommerset ${ }^{2}$ and Frank Nilsen ${ }^{1,4}$
}

\author{
Address: ${ }^{1}$ Department of Population Genetics and Ecology, Institute of Marine Research, 5817 Bergen, Norway, ${ }^{2}$ Intervet Norbio AS, 5008 Bergen, \\ Norway, ${ }^{3}$ Department of Health, Institute of Marine Research, 5817 Bergen, Norway and ${ }^{4}$ Department of Biology, University of Bergen, 5020 \\ Bergen, Norway \\ Email: Rasmus Skern-Mauritzen* - rasmus@imr.no; Petter Frost - petter.frost@sp.intervet.com; Sussie Dalvin - sussie@imr.no; \\ Bjørn Olav Kvamme - bjornok@imr.no; Ingunn Sommerset - ingunn.sommerset@sp.intervet.com; Frank Nilsen - frankn@imr.no \\ * Corresponding author
}

Published: 13 May 2009

BMC Molecular Biology 2009, 10:44 doi:10.1 186/1471-2199-10-44

This article is available from: http://www.biomedcentral.com//47/-2/99//0/44

(C) 2009 Skern-Mauritzen et al; licensee BioMed Central Ltd.

This is an Open Access article distributed under the terms of the Creative Commons Attribution License (http://creativecommons.org/licenses/by/2.0), which permits unrestricted use, distribution, and reproduction in any medium, provided the original work is properly cited.
Received: 19 December 2008

Accepted: 13 May 2009

\begin{abstract}
Background: Trypsin-like serine proteases are involved in a large number of processes including digestive degradation, regulation of developmental processes, yolk degradation and yolk degradome activation. Trypsin like peptidases considered to be involved in digestion have been characterized in Lepeophtheirus salmonis. During these studies a trypsin-like peptidase which differed in a number of traits were identified.
\end{abstract}

Results: An intronless trypsin-like serine peptidase (LsTryp /0) from L., salmonis was identified and characterized. LsTryp 10 mRNA is evenly distributed in the ovaries and oocytes, but is located along the ova periphery. LsTryp 10 protein is deposited in the oocytes and all embryonic cells. LsTryp 10 mRNA translation and concurrent degradation after fertilization was found in the embryos demonstrating that LsTryp 10 protein is produced both by the embryo and maternally. The results furthermore indicate that LsTryp 10 protein of maternal origin has a distribution pattern different to that of embryonic origin.

Conclusion: Based on present data and previous studies of peptidases in oocytes and embryos, we hypothesize that maternally deposited LsTryp 10 protein is involved in regulation of the yolk degradome. The function of LsTryp 10 produced by the embryonic cells remains unknown. To our knowledge a similar expression pattern has not previously been reported for any protease.

\section{Background}

Trypsin-like serine peptidases of the S1A subfamily (hereafter referred to as S1A peptidases) are found in all metazoan groups and are involved in a variety of biological processes $[1,2]$. They are synthesized as inactive zymogens which are activated by proteolytic cleavage at a defined site N-terminal to the proteolytic domain. They may consist of the proteolytic domain only (referred to as single domain peptidases) or may contain one or more additional domains, generally $\mathrm{N}$-terminal to the proteolytic domain (referred to as multi domain peptidases). S1A peptidases are generally extracellular peptidases although some have intracellular functions [2,3]. S1A peptidases involved in digestion commonly consist of a proteolytic domain only, but single domain S1A peptidases may exhibit strict specificity and serve regulatory roles [4-6]. 
However, regulatory S1A peptidases generally include one or more additional domains $[2,5,7]$. Trypsins are S1A peptidases with a specific architecture that cleave substrates after Arg and Lys [2]. They are common digestive enzymes in metazoans and their zymogens are activated by trypsins or enteropeptidases [2]. Once activated, the digestive trypsins contribute to the proteolysis of ingested proteins and also activate other digestive zymogens such as chymotrypsinogens and proelastases [2].

S1A peptidases also play important roles during fertilization and early development; at fertilization S1A peptidases are necessary to prevent polyspermy by catalyzing formation of a fertilization envelope $[8,9]$ and in the early embryo, S1A peptidases participate in developmental control $[10,11]$ and cell migration $[12,13]$. Egg yolk degradation has been reported to be catalyzed both by aspartic and cysteine cathepsins and serine peptidases, including S1A peptidases [14-20]. S1A peptidases involved in egg yolk degradationare suggested mainly to serve in degradome activation $[14,17,21]$, but it should be noted that the main mechanism controlling activation of yolk degrading proteases appears to be decreasing yolk granule $\mathrm{pH}[14,15,22]$.

Proteins needed before the midblastula transition are supplied maternally or encoded by maternal mRNA. S1A peptidases exerting their role in the embryos prior to the midblastula transition appear to be transcribed and translated either maternally [23] or by germ line cells other than the oocyte [10]. Proteases involved in, or putatively involved in, yolk degradation generally appear to be translated before fertilization [24-26] although embryonic transcription and translation of a vitellogenin degrading S1A peptidase has been reported in Bombyx mori [18]. However, the exact spatiotemporal patterns of transcription and translation are unknown for many peptidases active during early development. Maternal transcripts have been reported to comprise transcripts from more than $50 \%$ of the protein encoding genes in an organism $[27,28]$. However, detailed studies of maternally encoded S1A peptidases have not been reported previously.

Salmon lice (L. salmonis) are obligate ectoparasites on salmonid fishes and a major pest in salmon aquaculture. Adult female salmon lice are fertilized by males that deposit spematophores at the genital segment [29]. At regular temperature dependent intervals (approximately 10 days at $10^{\circ} \mathrm{C}$ (personal observations)) they produce a pair of eggstrings (containing $\leq 1500$ eggs) that are fertilized when they are extruded [29]. During characterization of trypsins and trypsin-like peptidases in L. salmonis [30-33] we identified an intronless single domain trypsin that was transcribed by adult female L. salmonis (LsTryp10, accession\# EF490878). In the present study LsTryp10 is characterized and functional implications are discussed.

\section{Results \\ Sequence analysis}

EST sequencing led to identification of a 1052 b.p. transcript encoding a serine proteinase named LsTryp10. The transcript consist of a 810 b.p. ORF, a 37 b.p. 5' untranslated region (UTR) and a 205 b.p. 3' UTR. Alignment of genomic and corresponding cDNA sequences revealed that LsTryp10 is devoid of introns. The protein was predicted to be secreted from the cell using the analytical strategy recommended by Emanuelsson et al. [34]. The encoded 270 amino acid (a.a.) protein with a predicted weight of $30 \mathrm{kDa}$ consist of a putative 17 a.a. signal peptide, a 10 a.a. activation peptide and a 243 a.a. proteolytic domain. The proteolytic domain in the predicted protein includes the catalytic triad His57, Asp102 and Ser195 in a sequence context typical for proteinases of the S1A subfamily in addition to residues characteristic for S1A peptidases with trypsin specificity, including Tyr172, Asp189, Gln192, Gly216 and Gly226 (chymotrypsinogen numbering [35]). The encoded trypsinogen appear to contain the 3 cysteine bridges conserved in S1A peptidases [36] and an additional cysteine bridge between Cys106 and Cys129. However, LsTryp10 do not contain the disulphide bridge (Cys59 to Cys104) conserved in previously described single domain trypsins from L. salmonis [31]. The overall identity to previously published trypsins from L. salmonis $[30,31,37]$ was $\leq 33 \%$.

\section{Phylogenetic analysis}

The phylogenetic analysis shows that vertebrate, crustacean and insect trypsins reside on separate well-supported branches (Fig. 1). Furthermore the vertebrate acrosins, found in sperm cells, form a distinct group within a wellsupported monophyletic clade that includes Cortex Granule Serine Protease 1 (CGSP1) found in sea urchin eggs. Most of the internal nodes in the phylogenetic tree were not supported (Fig. 1) due to the high frequencies of highly conserved and highly divergent residues resulting in relatively low prevalence of informative semi-conserved residues. LsTryp10 does not appear to be closer related to previously characterized $L$. salmonis single domain trypsins [31] than to any of the other supported trypsin branches. It should be noted that although LsTryp10 resides on the same branch as the clip domain containing serine peptidase LsCSP1 [33] this position is not supported (Fig. 1).

\section{Stage specific LsTryp 10 transcription and size confirmation}

A single transcript of approximately 1200 b.p. was identified in the northern hybridization analysis (Fig. 2). This corresponds well with the 1073 b.p. cDNA sequence. In northern blot analyses LsTryp10 mRNA was undetectable in adult males but present in mature females and unfertilized eggstrings (Fig. 2). This pattern was confirmed by QPCR analyses where LsTryp10 mRNA was present at back- 


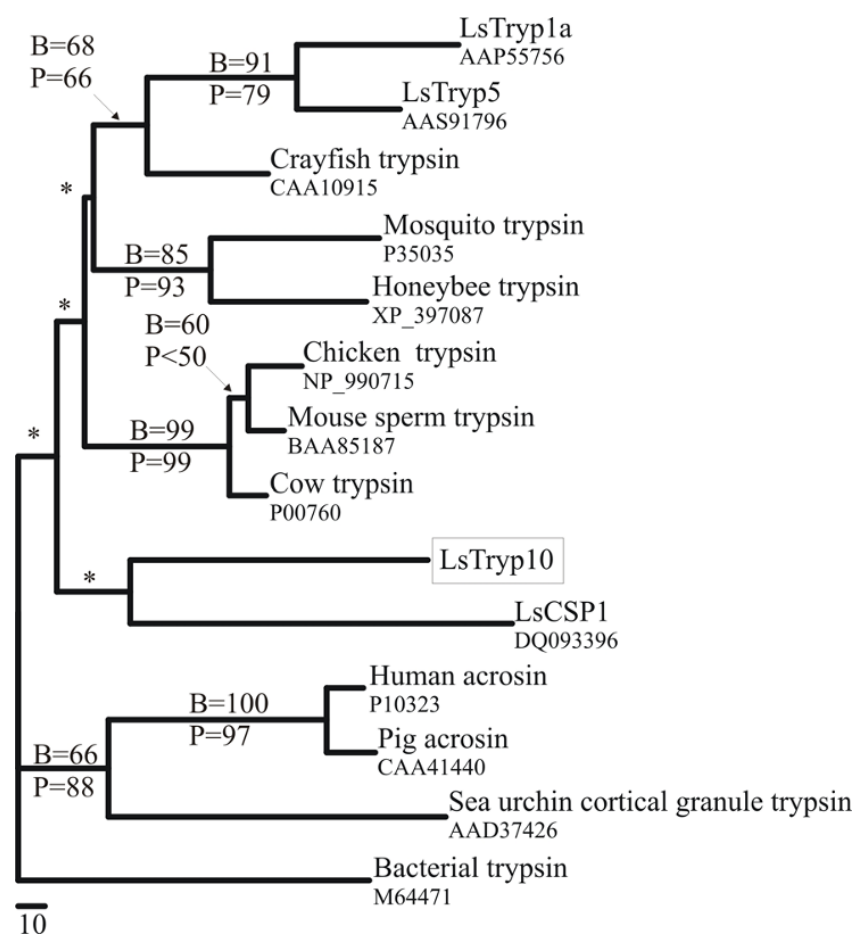

Figure I

Maximum likelihood tree. The tree was generated by the Proml module in the Phylip package. Phylogenetic analysis of selected SIA peptidases. Support was calculated by bootstrapping $(B)$ and quartet puzzling $(P)$. Unsupported branches are indicated by $*$. Bacterial trypsin was used as outgroup. Accession numbers are indicated in the tree.

ground levels in preadult stages and adult males, but was significantly upregulated in adult females (Fig. 3). Microarray analysis have furthermore shown that LsTryp10 transcript abundance increase during development after the last molt in females (Contig 328 in Eichner et al. [38]).

\section{Localization of LsTryp 10 mRNA}

In situ hybridization showed that LsTryp10 mRNA was present in the ovary and in the oocytes throughout the oviduct (Fig. 4F-J). LsTryp10 mRNA is homogenously dispersed in the oocytes localized in the anterior part of the oviducts in cephalothorax. Upon entry into the genital segment the oocytes expand substantially in size, apparently due to incorporation of granules and lipids, and LsTryp10 mRNA becomes localized to the periphery of the ova (Fig. 4F).

\section{Yolk lumen acidification, LsTryp I 0 protein localization, translation and mRNA degradation}

LsTryp10 protein was found in embryos and unfertilized mature eggs. In the unfertilized oocytes inside the genital segment LsTryp10 was distributed along the oocyte periphery and in patches associated with yolk granules

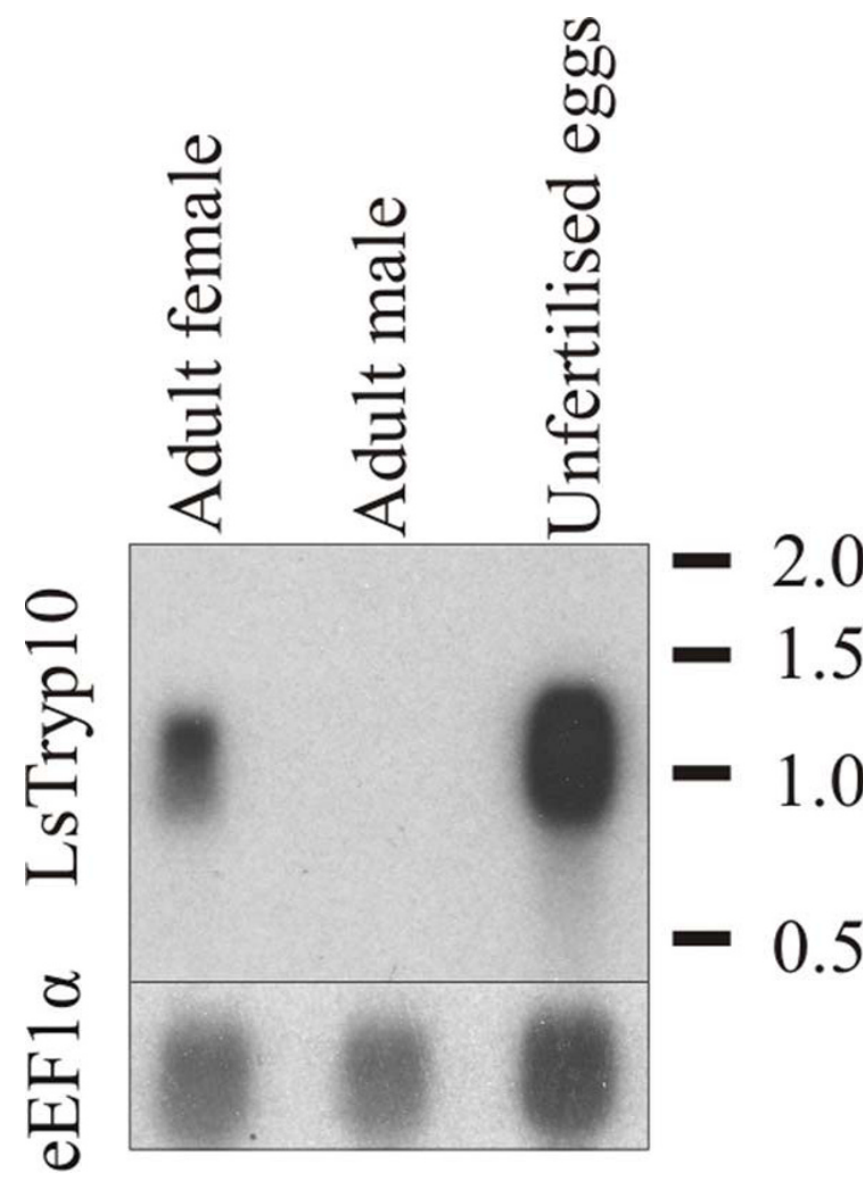

Figure 2

Northern blot analysis of LsTryp I 0 and eEF I $\alpha$. Northern blot analysis showing the size of LsTryp 10 and relative LsTryp I 0 and eEFI $\alpha$ transcript levels in adult females, males and unfertilized eggs. Loaded total RNA was approximately $4.5 \mu \mathrm{g}$ RNA pr. well. Exposure times for LsTryp 10 and eEFI $\alpha$ are dissimilar.

(Fig. 5A). After fertilization, LsTryp10 was also shown to be present throughout the embryonic cells and in patches associated with yolk granules (Fig. 5C, D). Negative controls were performed without primary antibodies and confirmed specific staining. Relative quantification showed that the LsTryp10 protein level in the fertilized eggs increased between 1 hour and 48 hours after fertilization and then remained stable, whereas the encoding LsTryp10 mRNA level decreased steadily from 1 to 192 hours after fertilization (Fig. 6). In contrast the LsTryp10 mRNA level in unfertilized eggs appeared relatively stable between 1 and 108 hours after extrusion and then decreased to a level comparable to that found in fertilized eggs 192 hours after fertilization (Fig. 6). The yolk compartment was shown to be acidic at day 5 after fertilization by exposing embryos to LysoTracker, whereas no indica- 


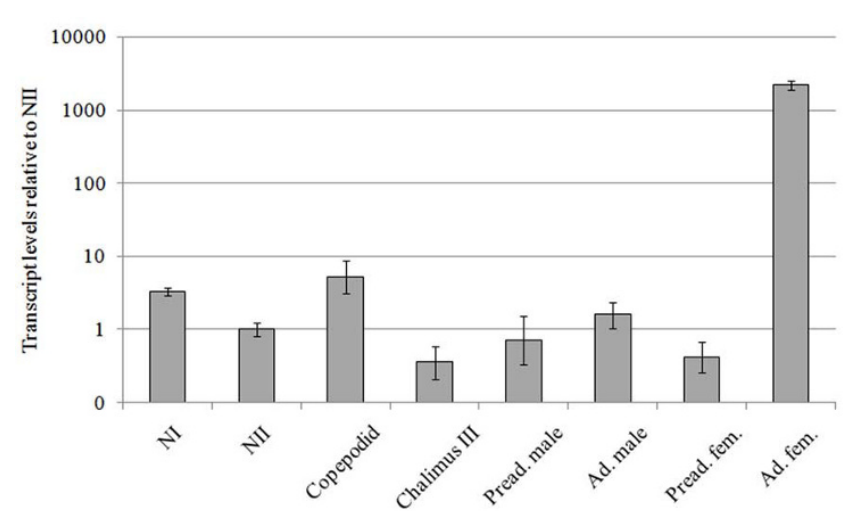

Figure 3

LsTryp 10 transcript levels. LsTryp 10 transcript levels at different developmental stages quantified relative to the level found in the nauplius II (NII) stage. Error bars show 95\% c.i. calculated from the $\Delta \Delta \mathrm{C}_{\mathrm{T}}$ values from each dilution. The error bars for NII show the $95 \%$ c.i. calculated from the $\Delta \mathrm{C}_{\mathrm{T}}$ values. Note the logarithmic vertical axis.

tions of acidic compartments were identified elsewhere in the embryo (results not shown).

\section{Discussion}

The results show that LsTryp10 encodes a peptidase that includes the catalytic triad residues (His, Asp and Ser) in a context typical for serine peptidases of the S1A clan in addition to the specificity determinants for trypsin [4]. Transcript length and presence was confirmed by northern blot analysis (Fig. 2). Interestingly, LsTryp10 is devoid of introns, which is a feature also reported for functional digestive trypsins in Anopheles gambiae [39]. The phylogenetic analysis do not indicate a reliable phylogenetic position for LsTryp10, which appears no closer related to other single domain trypsins from L. salmonis [30,31,33,37] than to bacterial trypsin or the clip domain containing LsCSP1 [33]. CGSP1, which is thought to activate the fertilization envelope and prevent polyspermy in sea urchins [8], appears to be closer related to acrosins than to the other serine peptidases included in the analysis. Since this may give the impression that S1A peptidases related to fertilization form a monophyletic assemblage it should be noted that mouse TESP4 which is suggested to have a fertilization related function [40], resides on a well supported branch with pancreatic trypsin from cow and chicken (Fig. 1).

Background LsTryp10 transcription is detected in all investigated L. salmonis stages except adult females where it is upregulated more than 2000 -fold relative to the level in nauplius II larvae (Fig. 3). In situ hybridization results show that LsTryp10 mRNA is transcribed in the ovary. LsTryp10 transcripts are evenly distributed in the imma- ture oocytes in the anterior oviduct in cephalothorax (Fig. $4 \mathrm{H}, \mathrm{J})$, but are located along the periphery of the ova in the genital segment (Fig. 4F). The change in distribution of LsTryp10 mRNA indicates that the transcripts are actively localized in the egg, as are the transcription factor bicoid mRNA in Drosophila melanogaster and the transforming growth factor $V g 1$ mRNA in Xenopus laevis [41,42]. The 3' UTR in LsTryp10 mRNA is substantially longer (205 b.p.) than the 3'-UTRs (44-104 b.p.) in previously characterized L. salmonis S1A peptidases [30,31,33,37]. Considering that localization of many transcripts, including bicoid mRNA and Vg1 mRNA, depends on elements in their 3' UTRs [41-45] the relatively long LsTryp10 mRNA 3' UTR may contain elements involved in control of mRNA localization and translation.

The distribution of LsTryp10 mRNA suggests that it is a maternal transcript. This notion appears to be supported by the simultaneous LsTryp 10 mRNA translation and degradation after fertilization (Fig. 6). However, immunohistochemical studies demonstrate this perception to be incorrect as LsTryp10 protein is found in oocytes inside the female's genital segment as well as in most embryonic cells (Fig. 5). The question then arises: Is the embryonic LsTryp 10 protein encoded by maternal mRNA? The first cleavage in order Siphonostomatoida (which includes $L$. salmonis) is holoblastic but strongly unequal with the smaller cell giving rise to the embryonic cells and the larger cell containing most of the yolk [46-48]. A similar development in L. salmonis must be expected which implies that only a small fraction of the deposited maternal mRNA is present in the embryonic cells. The stable level of LsTryp10 mRNA in developing eggs (Fig. 6) may thus be the product of a simultaneous degradation of maternal LsTryp10 mRNA in the large yolk containing cell and zygotic transcription of LsTryp10 mRNA in the developing embryonic cells [47-49]. The very low expected levels of maternal LsTryp10 encoding transcripts inside the embryonic cells thus strongly indicates that LsTryp 10 protein translated after fertilization is encoded by zygotically transcribed LsTryp10 mRNA. It is plausible that the maternal and zygotic LsTryp10 mRNAs are encoded by paralog genes.

In the oocytes, maternally deposited LsTryp10 protein (mLsTryp10) was found along the periphery and in patches associated with vitellogenin granules inside the yolk compartment (Fig 5). This yolk associated localization resembles the reported distribution of an Artemia trypsin-like peptidase with a putative degradome activating function [50] as well as other peptidases putatively involved in yolk degradation or degradome activation $[17,51,52]$. Earlier reports suggest, that serine peptidases are not directly responsible for yolk degradation but activate a second set of peptidases (generally cathepsins) that 


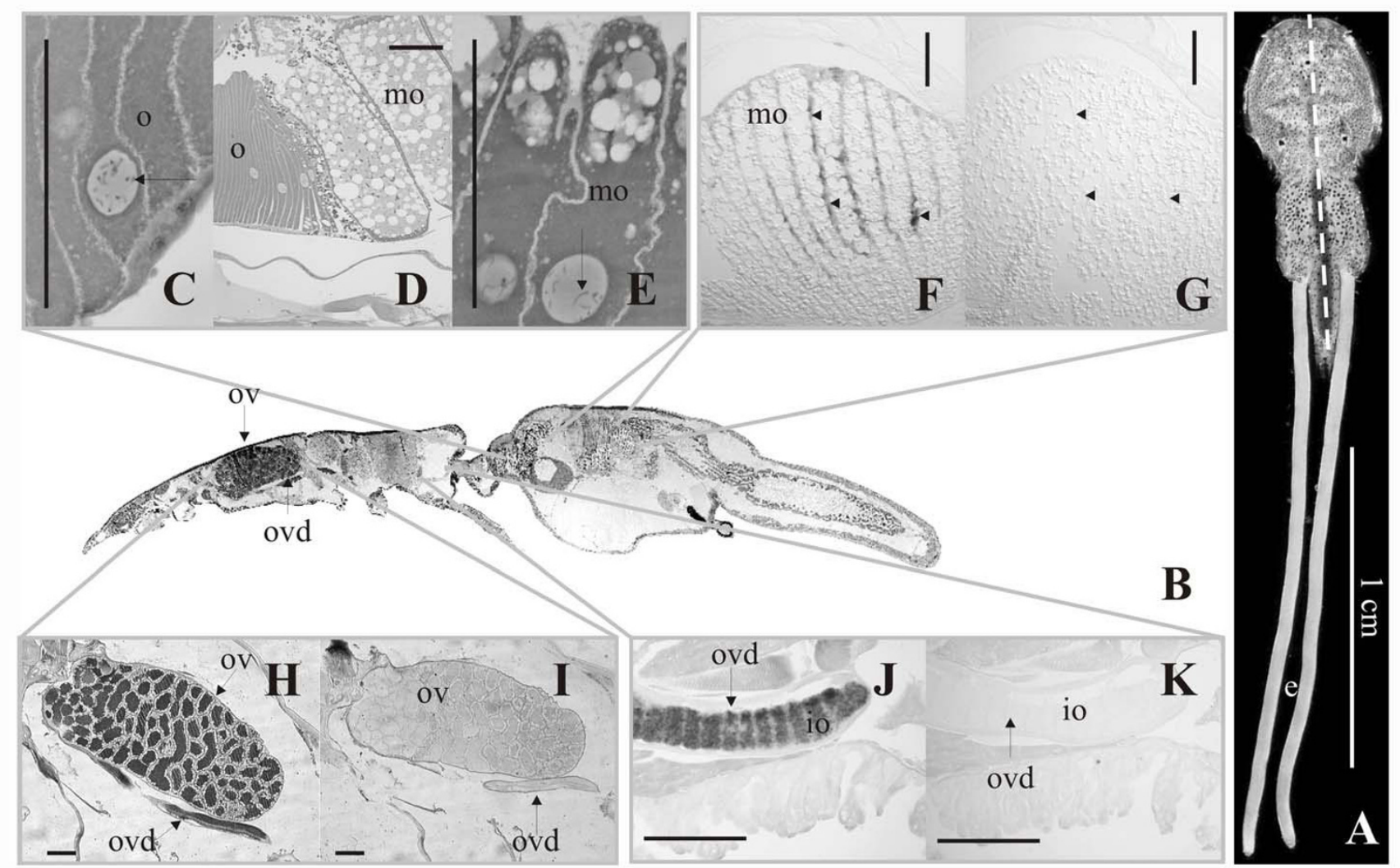

Figure 4

LsTryp 10 mRNA localization and histology. A. Adult female L. salmonis with eggstrings, broken white line indicates location of section shown in B. e: eggstrings. B. Section of adult female L. salmonis. ov: ovary; ovd: oviduct. C. Immature oocytes (o) in the oviduct. D. Transition from immature oocytes in the oviduct (C) to mature oocytes in the genital segment (E). E. Mature oocytes (mo) in the genital segment after being filled with droplets and granules. Note that the chromosomes appear to be in the pachytene or diplotene stage both in the immature and mature oocytes (arrows in $\mathbf{C}$ and $\mathbf{E}$ ). ISH using antisense $(\mathbf{F}, \mathbf{H}, \mathbf{J})$ and sense $(\mathbf{G}, \mathbf{I}, \mathbf{K})$ RNA probes show that LsTryp 10 mRNA is present in the ovary (ov), in immature oocytes (io) in the oviduct (ovd) as well as in mature oocytes in the unfertilized eggstring (ufe). In the mature oocytes LsTryp I0 mRNA is localized along the oocyte periphery (arrowheads in F, corresponding locations in negative control (G) also marked with arrowheads). Bar $=1 \mathrm{~cm}$ in $\mathbf{A}, 100 \mu \mathrm{m}$ in $\mathbf{C}-\mathbf{K}$.

perform the degradation of the yolk $[14,17,21]$. A similar function for mLsTryp10 protein is likely. Yolk degradation appear to be initiated by yolk granule acidification in many invertebrate species $[15,22,52,53]$. This may also be the case in L. salmonis as we observed acidic conditions in the yolk compartment in 5 days old embryos. It is possible that acidification leads to autoactivation of mLsTryp 10 protein that in turn activates the general yolk degradome. The LsTryp10 protein translated by the embryo (eLsTryp10) is found in all embryonic cells, including cells in the antennae (Fig. 5D) which indicate that eLsTryp 10 has a function not related to egg yolk degradation. Based on the ubiquitous distribution of eLsTryp10 it is likely to be involved in general developmental processes such as modification of the cell-matrix e.g. associated with cell movement $[12,13]$
In conclusion, LsTryp10 is a trypsin which is both deposited in the oocytes and translated after fertilization. Maternally deposited and embryonic LsTryp 10 seems to be translated from different pools of mRNA; one maternally transcribed and one transcribed after fertilization. The deposited LsTryp10 is likely to be involved in egg yolk degradation whereas embryonic LsTryp10 appears to serve a different purpose, e.g. cell matrix modification. LsTryp10 is the first arthropod peptidase reported to be both maternally deposited and translated in developing embryos.

\section{Conclusion}

An intronless trypsin-like serine peptidase, LsTryp10, was characterized in L. salmonis. LsTryp10 mRNA was significantly upregulated in adult females relative to all other 

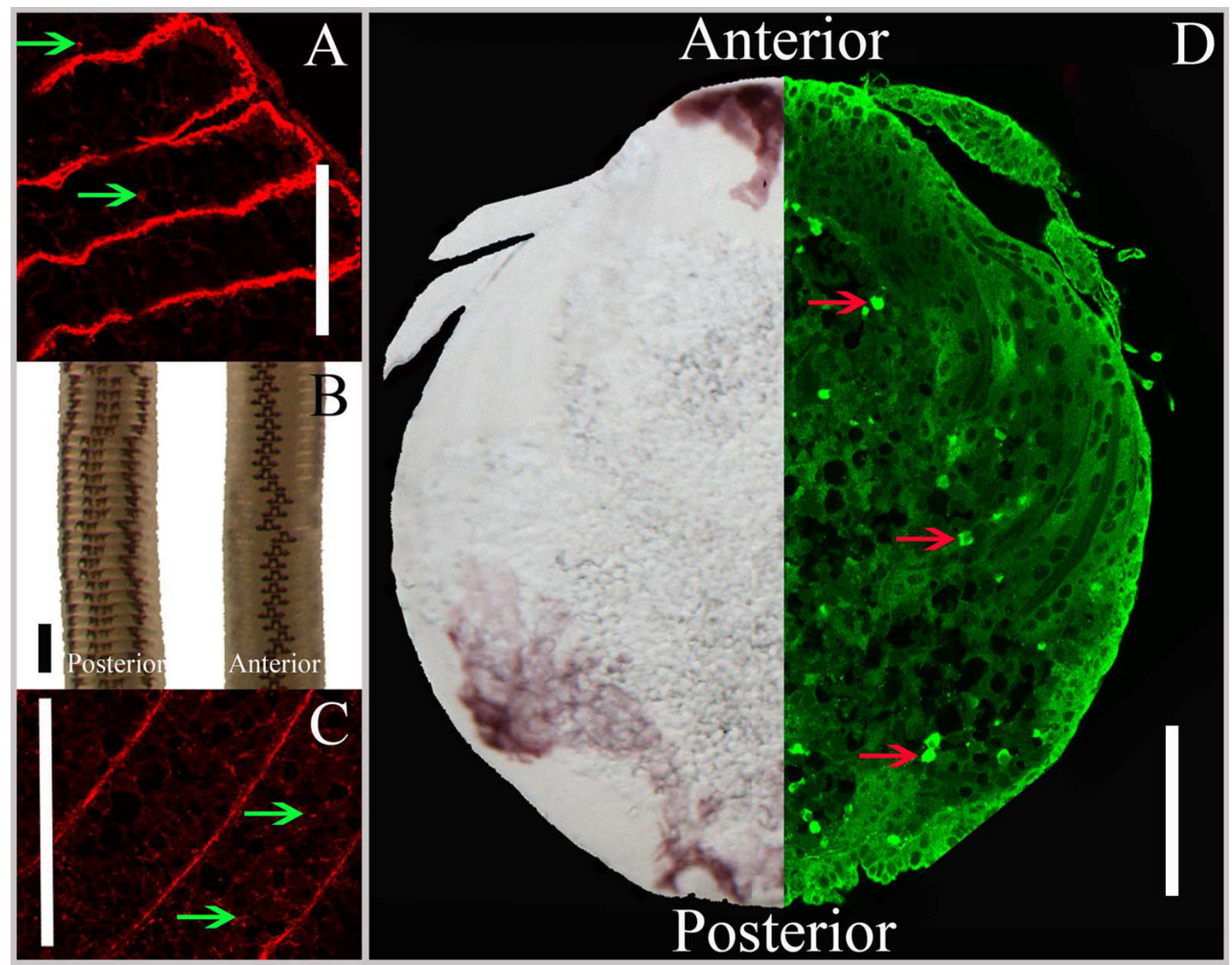

Figure 5

Immunolocalization of LsTryp I0. A and C: Confocal section showing the peripheral and yolk associated (green arrows) localization of LsTrypIO (red) in unfertilized oocytes within adult females (A) and in fertilized eggs 30 minutes after fertilization (C). B: Fertilized eggstrings 8 days after fertilization. D: Left side: Boiled embryo 5 days after eggstring fertilization. Note the localization of the yolk compartment (granular content). Right side: Confocal section showing localization of LsTryp I0 (green) in the embryonic tissue and associated with yolk granules (red arrows). Bars indicate $225 \mu \mathrm{m}$ in B and $100 \mu \mathrm{m}$ in A, C and D.

investigated stages. LsTryp10 mRNA was found in the ovaries, oviducts, ova and developing embryos. The encoded protein was found in ova as well as in developing embryos where it was also shown to be translated. Considering the pattern of the first cell divisions in L. salmonis, the present results indicate that LsTryp10 proteins in the embryos stem from two distinct lines of synthesis. First maternally transcribed and translated LsTryp10 protein is deposited in the oocytes and second embryonically transcribed LsTryp10 mRNA is translated in all embryonic cells. The maternally produced LsTryp 10 protein is likely to be involved in yolk degradation or yolk degradation control, whereas the function of embryonically produced LsTryp10 protein is unknown.

\section{Methods}

\section{Handling and sampling of fishes and parasites}

L. salmonis were cultured on Atlantic salmon (Salmo salar (Linnaeus)) as described previously [31]. L. salmonis for quantitative real-time PCR (Q-PCR) analysis were sampled as nauplius I larvae ( $\approx 10000)$, nauplius II larvae $(\mathrm{n} \approx 10000)$, infectious copepodids $(\mathrm{n} \approx 5000)$, chalimus III $(\mathrm{n}=35)$, preadult I\&II males mixed $(\mathrm{n}=10)$, preadult $\mathrm{I}$ females $(\mathrm{n}=10)$, adult males $(\mathrm{n}=16)$ and adult females $(\mathrm{n}=10)$. L. salmonis for Q-PCR and cDNA sequencing 


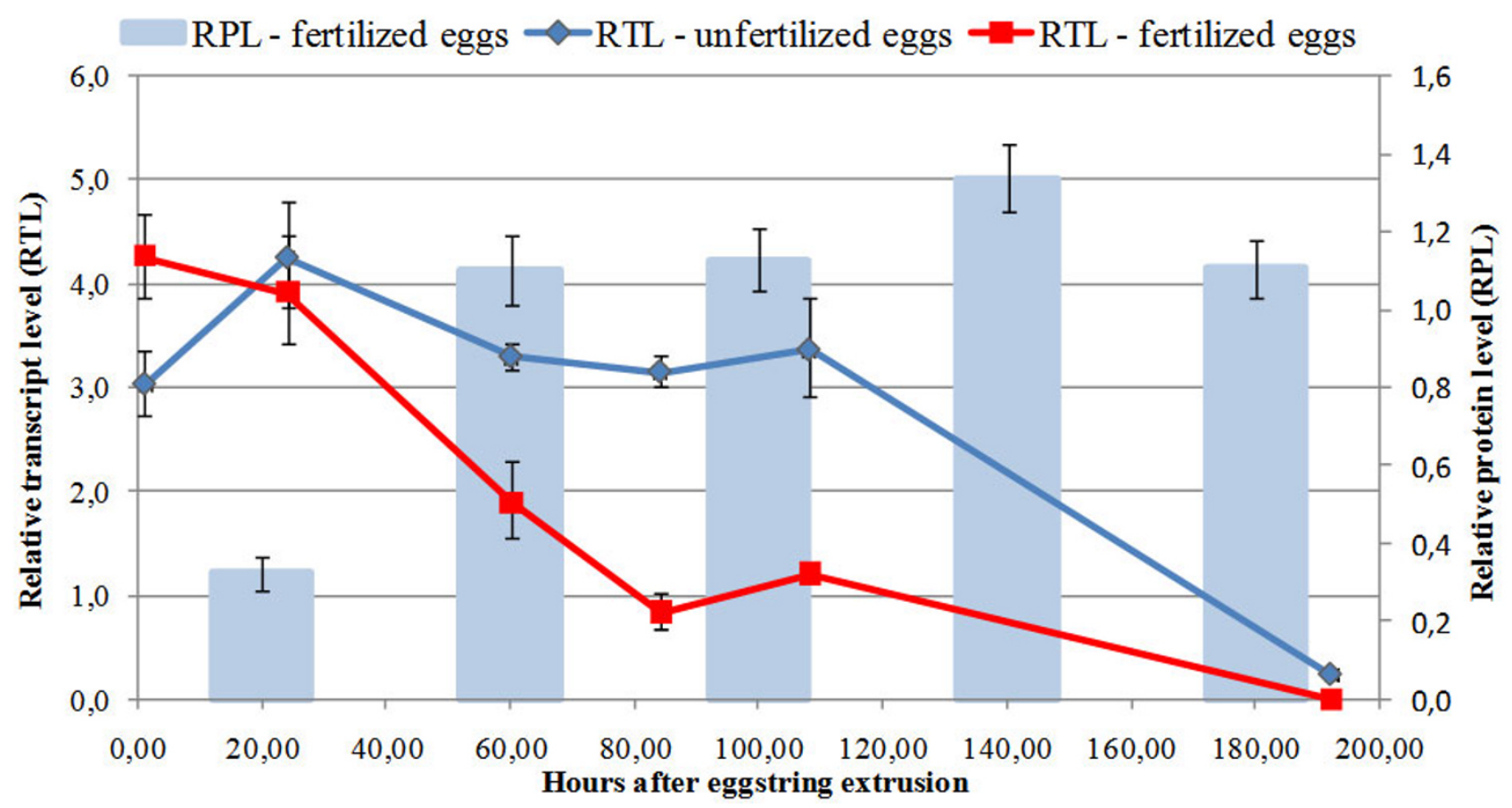

Figure 6

Relative protein and mRNA levels in developing embryos. Relative LsTryp 10 encoding transcript levels in unfertilized and developing fertilized eggs (RTL - see text for details) determined by Q-PCR. The connective lines are added for clarity and do not necessarily reflect transcript level progression. The relative LsTryp 10 protein levels (RPL) in developing fertilized eggs determined by ELISA studies are also shown. Error bars indicate $95 \%$ c.i.

were stored in RNA later (Ambion, Huntingdon, UK), for 24 hours at $4{ }^{\circ} \mathrm{C}$ and then at minus $20^{\circ} \mathrm{C}$. Adult females used for isolation of genomic DNA were stored in $70 \%$ ethanol. Eggstrings for transcript quantification were sampled from fertilized females and unfertilized females. These were obtained by incubating preadult II females on salmon (not previously infected) with and without adult L. salmonis males. The copulative statuses for the groups were confirmed by visual examination for spermatophores. The eggstrings were sampled at 1 hour $( \pm 30 \mathrm{~min}-$ utes), 24 hours ( \pm 4 hours), 60 and 108 hours (both \pm 8 hours) after fertilization and stored at $-80^{\circ} \mathrm{C}$. Eggstrings for protein analysis were sampled after 1 hour $( \pm 30 \mathrm{~min}-$ utes) and 48,72 , and 96 hours (all \pm 8 hours).

\section{Sequencing of gDNA and full-length CDNA}

Expressed Sequence Tags (ESTs) from L. salmonis were obtained as described previously [31] and are described in Eichner et al. [38]. The trypsin encoding EST clone with the longest insert was selected and completely sequenced on both strands using primer walking. Additional 5' sequence was obtained as described previously [31]. Based on the obtained cDNA sequences, primer pairs for genomic PCRs were constructed and the resulting PCR products were cloned and more than 30 clones were com- pletely sequenced on both strands using primer walking. Additional genomic sequence was obtained using the GenomeWalker kit in accordance with the manufacturers instructions (Clonetech, Mountain view, California, USA).

\section{Northern blot hybridization analyses}

Total RNA was purified from unfertilized eggstrings, an adult male and an adult female $L$. salmonis using TRIZOL ${ }^{\circledR}$ following the manufacturers recommendations (Life Technologies, Gaithersburg, Maryland, USA). Northern blotting was performed using approximately $4.5 \mu \mathrm{g}$ RNA per well and sequence specific [32P] labeled DNA probes against the LsTryp10 ORF and the homogeneously transcribed $e E F 1$ [54]. Membranes were prehybridized 30-60 min. at $68^{\circ} \mathrm{C}$ in PerfectHyb solution (Sigma-Aldrich Norway, Oslo, Norway). Denatured probes were added and incubation was continued over night. After washing twice for $10 \mathrm{~min}$. at $68^{\circ} \mathrm{C}$ in $0.1 \times \mathrm{SSC} / 0.1 \times \mathrm{SDS}$, signals from the membrane were detected using Kodak BioMax MS XRay film (Kodak, Rochester, New York, USA).

\section{Bioinformatic analysis}

Sequence handling and editing was done using Vector NTI 9.1.0 (Invitrogen, Carlsbad, California, and USA.) and 
GeneDoc http://www.psc.edu/biomed/genedoc. For analysis of a plausible protein location the translated LsTryp10 sequence was analyzed by submission to TargetP 1.1 [55], SignalP 3.0 [56], TMHMM 2.0 [57], TMBETA-NET [58] and big-PI [59] according to the suggestion by Emanuelsson et al. [34]. Phylogenetic analyses of selected amino acid sequences corresponding to the mature peptidases were performed using the Phylip package [60] and TreePuzzle v. 5.2 [61]. Mutation rate heterogeneities were calculated in Tree-Puzzle using the JTT model and 8 rate heterogeneities. The distribution coefficient $\alpha$ was 0.93. A maximum likelihood tree was generated by Proml in the Phylip package (jumbling 10 times) and support was calculated by bootstrapping (100 replicates in Phylip) and puzzling (10000 times in Tree-Puzzle).

\section{Relative quantification of LsTryp I0 mRNA levels}

The transcript levels during the L. salmonis life cycle and in eggstrings at different ages after fertilization were determined by Q-PCR using ABI 7900 HT (eggs and embryos) and ABI 7700 (adults and larval stages) PCR Systems (Applied Biosystems, Foster City, California, USA) at standard settings. The real-time primers and probe were: Forward primer: TTG CAA GAC CGG AAC AAG AAC. Reverse primer: CAA ATC TGA GTA CAC CCC AAC CT. Probe: 6FAM-CAA CTA CAA GAG GTG TCC CAT CCG GG-TAMRA. The real time assays were performed as previously described [31] with the modification that additional TurboDNase (Ambion, Huntingdon, UK) treatments were performed on the RNA from nauplius I and II, chalimus III and preadult males and females. The results were analyzed by the $\Delta \mathrm{C}_{\mathrm{T}}$ approach [62] as described previously [31]. The 95\% c.i. values at each developmental stage presented in Fig. 3 were calculated from the average $\Delta \Delta \mathrm{C}_{\mathrm{T}}$ values for each dilution, except for nauplius II (which was used as calibrator thereby defining the average $\Delta \Delta \mathrm{C}_{\mathrm{T}}$ values as 0 for this stage). For nauplius II the $95 \%$ c.i. shown in Fig. 3 was calculated from the average $\Delta \mathrm{C}_{\mathrm{T}}$ at each dilution. The results were confirmed by analysis using a kinetic approach [63] as earlier suggested [64].

For determination of relative LsTryp10 mRNA levels in eggs, total RNA from four pairs of eggstrings for each sampled time point was isolated in TRI REAGENT (SigmaAldrich Norway, Oslo, Norway) using a FastPrep homogenizer and Lysing Matrix D (Q-Biogene, Solon, Ohio, USA). Extracted RNA was treated with TURBO DNAse (Ambion, Huntingdon, UK) and added $0.5 \mathrm{U} / \mu \mathrm{l}$ SUPERase $\mathrm{In}^{\mathrm{TM}}$ (Ambion, Huntingdon, UK). Excellent quality and integrity of the RNA was confirmed using a Bioanalyzer according to the manufacturers instructions (Agilent, Santa Clara, California, USA.). Concentrations were adjusted to $100 \mathrm{ng} / \mu \mathrm{l}$ following quantification on a NanoDrop ND 1000 spectrophotometer (Thermo Fisher Scientific, Waltham, Massachusetts, USA) and diluted in two fold series from $100 \mathrm{ng} / \mu \mathrm{l}$ to $6.25 \mathrm{ng} / \mu \mathrm{l}$. The cDNA syntheses and Q-PCRs were conducted independently at each dilution as previously described [31] with the exception that cDNA was made using MultiScribe reverse transcriptase according to the manufacturers recommendations (Applied Biosystems, Foster City, California, USA). Relative expression levels were expressed as $\Delta \mathrm{C}_{\mathrm{T}}$ relative to the mean transcript level in all the sampled eggstrings using the following formula:

$$
\Delta \mathrm{C}_{\mathrm{T}}=\mathrm{C}_{\mathrm{T} \text { mean*dilution }}-C_{\mathrm{T} \text { sample*dilution }}
$$

Where $\mathrm{C}_{\mathrm{T} \text { mean }}{ }^{*}$ dilution is the mean of the $\mathrm{C}_{\mathrm{T}}$ values of all samples at a given dilution and $\mathrm{C}_{\mathrm{T} \text { sample }}$ dilution is the mean $\mathrm{C}_{\mathrm{T}}$ value of the sample parallels at a given dilution. The relative transcript levels (RTL) presented in Fig. 5 are calculated as $R E=2^{\Delta C_{T}}$. The c.i. is calculated from the $\Delta C_{T}$ values from the five dilutions. The results were confirmed by analysis using a kinetic approach [64].

\section{Identification of LsTryp 10 mRNA localization}

The localization of LsTryp10 mRNA in adult female L. salmonis was determined by in situ hybridization as described previously [31] using a cDNA clone covering 669 base pairs (b.p.) of the open reading frame (ORF) as template for RNA probe synthesis. Hybridizations were performed with antisense probes to show localization of transcripts and with sense probes as negative controls. Labeled probes were visualized using anti-DIG alkaline phosphatase FAB fragment (Roche, Basel, Switzerland) and a chromogen substrate containing Levamisol (SigmaAldrich Norway, Oslo, Norway), NTB and BCIP (Roche, Basel, Switzerland).

\section{Histological analysis of $L$. salmonis}

Adult female L. salmonis were fixed in $4 \%$ paraformaldehyde in PBS, dehydrated in ethanol $(70 \%, 80 \%, 90 \%$ and $95 \%$ ) and subsequently embedded in Technovit 7100 following the manufacturers recommendations (Heraeus, Hanau, Germany). Sections $(2 \mu \mathrm{m})$ were produced using a microtome, stained with metachromatic toluidin and examined using a Leica DMRBE light microscope (Leica Microsystems, Wetzlar, Germany).

\section{Relative quantification of LsTryp I 0 protein levels in fertilized eggs}

The relative amounts of LsTryp10 protein in developing fertilized $L$. salmonis eggs were determined by enzyme linked immunosorbent assay (ELISA) using rabbit peptide antiserum raised against the peptide CEMHPGYSTSKQDN conjugated to keyhole limpet hemocyanin (BioGenes, Mannheim, Germany). The eggs (4 eggstring pairs from each sampled age) were cut in small pieces and 
homogenized by sonication in $250 \mu \mathrm{l} 50 \mathrm{mM}$ Tris, $1 \mathrm{mM}$ $\mathrm{NaCl}, 1 \mathrm{mM}$ EDTA, pH 10 while on ice. Sonication was performed with a microtip for a total of 60 seconds in short pulses ( $\leq 20$ seconds) followed by centrifugation at $3000 \mathrm{~g}, 4^{\circ} \mathrm{C}$ for 20 minutes. The water soluble protein concentration was normalized to $600 \mu \mathrm{g} / \mathrm{ml}$ using the Bio-Rad protein assay kit II as instructed by the manufacturer (BioRad, Hercules, California, USA.). ELISA was conducted according to Sommerset et al. [65] with the following modifications: After each incubation step, except after addition of conjugate, the ELISA plates were washed 3 times with PBST. Nunc-Maxisorb microplates (Thermo Fisher Scientific, Roskilde, Denmark) were coated $\mathrm{ON}$ at $4{ }^{\circ} \mathrm{C}$ with four dilutions $(50,25,12$ and 6 $\mu \mathrm{g} / \mathrm{ml}$ ) of the normalized protein solution, blocked at RT for one hour with 5\% non fat dry milk powder in PBST, and incubated for 2 hours at RT with antiserum diluted $1: 100$ in PBST containing $1 \%$ non fat dry milk powder (Sigma-Aldrich Norway, Oslo, Norway). Bound antibodies were detected by addition of HRP conjugated goatanti-rabbit ABs (BioRad, Hercules, California, USA, 1:2000 in PBST, 1\% non fat dry milk powder (Nestlé, Sandvika, Norway), 1 hour at RT), followed by 6 washes with PBST and incubation with $100 \mu \mathrm{l}$ o-Phenylenediamine $+\mathrm{H}_{2} \mathrm{O}_{2}$ according to instructions from the manufacturer. The chromogenic reaction was stopped after 20 minutes by addition of $50 \mu \mathrm{l} 2,5 \mathrm{~N} \mathrm{H}_{2} \mathrm{SO}_{4}$. Absorbances at $492 \mathrm{~nm}$ were measured for the above described antisera $\left(\mathrm{Abs}_{\text {test }}\right)$ and their corresponding preimmune sera $\left(\mathrm{Abs}_{\mathrm{bac}}\right.$ ground) from the same plates. The corrected absorbance $\left(\mathrm{Abs}_{\text {corr }}\right)$ was calculated as:

$$
\mathrm{Abs}_{\text {corr }}=\mathrm{Abs}_{\text {test }}-\mathrm{Abs}_{\text {bacground }}
$$

Relative protein levels (RPL) were calculated relative to the mean protein level in all the sampled eggstrings using the following formula:

$$
\mathrm{RPL}=\mathrm{Abs}_{\text {corr*sample }} / \mathrm{Abs}_{\text {corr }^{*} \text { dilution mean }}{ }_{\text {dilution }}
$$

Where $\mathrm{Abs}_{\text {corr*sample }}$ is the $\mathrm{Abs}_{\text {corr }}$ for a protein sample at a given dilution and Abscorr ${ }_{\text {* }}$ dilution mean*dilution is the mean Abs $_{\text {corr }}$ for all samples at that dilution. The c.i. was calculated from four parallel RPL values for each of the four dilutions. Pilot studies using the above design and the described peptide antiserum as well as five additional peptide antisera at various dilutions were conducted in advance to enable selection of the best serum and appropriate dilutions.

\section{Identification of LsTryp I 0 protein localization}

Developing embryos from eggstrings 5 days post fertilization were dissected and incubated in 4\% paraformaldehyde for 2 hours. Embryos were washed in PBS-AT (PBS, $1 \%$ albumin, $0.5 \%$ Triton-X) followed by blocking for 2 hours in 3\% albumin, PBS, $0.5 \%$ Triton-X. The embryos were subsequently incubated with the antiserum used for ELISA (as described above) diluted 1:100 for 20 hours and washed in PBS-AT for 2 hours followed by incubation with Alexa Flour 594 conjugated goat-anti rabbit antibody (Invitrogen, Carlsbad, California, USA.) diluted 1:200 over night. Samples were mounted using ProLong Gold with DAPI (Invitrogen, Carlsbad, California, USA.) Paraffin sections $(3 \mu \mathrm{m})$ were processed according to standard protocols. Slides were blocked with 3\% albumin and incubated for 16 hours with the above mentioned antiserum. Alexa Flour 594 conjugated goat-anti rabbit antibody (Invitrogen, Carlsbad, California, USA.) diluted 1:200 was used as a secondary antibody. Samples were mounted using ProLong Gold(Invitrogen, Carlsbad, California, USA.). Confocal imaging was performed with a Leica TCS SP2 AOBS microscope (Leica Microsystems, Wetzlar, Germany) at the Molecular Imaging Center (FUGE, Norwegian Research Council, University of Bergen). Parallel negative controls were performed without primary antibody. At similar confocal settings no signals were detected from negative controls (except for signal from DAPI where present).

\section{Embryonic LysoTracker assays}

Developing embryos were obtained as described in the previous section. The dissected eggs were immediately incubated in filtered sea water with $50 \mathrm{nM}$ LysoTracker (Invitrogen, Carlsbad, California, USA.) for 30 minutes. Embryos were then briefly washed in seawater and visualized as described above.

\section{Authors' contributions}

RSM and FN concieved the study, performed the sequence analyses and drafted the manuscript. RSM also performed quantitative real time PCR, in situ hybridization and protein quantification. PF helped coordinate the study and draft the manuscript. SD performed the immunohistochemical studies and helped to draft the manuscript. BOK sequenced cDNA and genomic DNA and helped draft the manuscript. IS helped quantifying protein levels. All authors read and approved the final manuscript.

\section{Acknowledgements}

We would like to thank Morten Arnesen, Per Gunnar Espedal, Ingrid Uglenes Fiksdal, Heidi Kongshaug and Dr. Ketil Malde for technical assistance and Dr. Christiane Eichner for fruitful discussions. This work has been financially supported by the Norwegian Research Council.

\section{References}

I. Krem MM, Di Cera E: Evolution of Enzyme Cascades From Embryonic Development to Blood Coagulation. Trends Biochem Sci 2002, 27:67-74.

2. Barrett AJ, Rawlings ND, Woessner JF: Handbook of proteolytic enzymes San Diego: Academic press; 1998.

3. Korkmaz B, Moreau T, Gauthier F: Neutrophil elastase, proteinase 3 and cathepsin G: Physicochemical properties, activity and physiopathological functions. Biochimie 2008, 90:227-242. 
4. Hedstrom L: Serine protease mechanism and specificity. Chem Rev 2002, I02:450I-4524.

5. Volanakis JE, Narayana SV: Complement factor $D$, a novel serine protease. Protein Sci 1996, 5:553-564.

6. Adham IM, Klemm U, Maier WM, Hoyer-Fender S, Tsaousidou S, Engel W: Molecular cloning of preproacrosin and analysis of its expression pattern in spermatogenesis. Eur J Biochem 1989, 182:563-568.

7. Krem MM, Rose T, Di Cera E: Sequence Determinants of Function and Evolution in Serine Proteases. Trends in Cardiovascular Medicine 2000, 10:17I-176.

8. Haley SA, Wessel GM: Regulated proteolysis by cortical granule serine protease I at fertilization. Mol Biol Cell 2004, 15:2084-2092.

9. Haley SA, Wessel GM: Proteolytic cleavage of the cell surface protein $\mathrm{p} 160$ is required for detachment of the fertilization envelope in the sea urchin. Dev Biol 2004, 272:19|-202.

10. Ye Y, Fortini ME: Proteolysis and developmental signal transduction. Semin Cell Dev Biol 2000, I I:2 I I-22I.

II. LeMosy EK, Tan YQ, Hashimoto C: Activation of a protease cascade involved in patterning the Drosophila embryo. Proc Nat Acad Sci USA 200I, 98:5055-5060.

12. Terada T, Okada Y, Nakanuma Y: Expression of matrix proteinases during human intrahepatic bile duct development. A possible role in biliary cell migration. Am J Pathol 1995, 147:1207-1213.

13. Drapkin PT, Monard D, Silverman AJ: The role of serine proteases and serine protease inhibitors in the migration of gonadotropin-releasing hormone neurons. BMC Dev Biol 2002, 2: I.

14. Giorgi F, Bradley JT, Nordin JH: Differential vitellin polypeptide processing in insect embryos. Micron 1999, 30:579-596.

15. Abreu LA, Valle D, Manso PP, Facanha AR, Pelajo-Machado M, Masuda H, Masuda A, Vaz I Jr, Lenzi H, Oliveira PL, Logullo C: Proteolytic activity of Boophilus microplus Yolk pro-Cathepsin D (BYC) is coincident with cortical acidification during embryogenesis. Insect Biochem Mol Biol 2004, 34:443-449.

16. Indrasith LS, Sasaki T, Yamashita O: A unique protease responsible for selective degradation of a yolk protein in Bombyx mori. Purification, characterization, and cleavage profile. J Biol Chem 1988, 263: 1045-I05I.

17. Medina M, Vallejo CG: A Serine Proteinase in Drosophila Embryos - Yolk Localization and Developmental Activation. Insect Biochemistry 1989, 19:687-691.

18. Ikeda M, Yaginuma T, Kobayashi M, Yamashita O: Cdna Cloning, Sequencing and Temporal Expression of the Protease Responsible for Vitellin Degradation in the Silkworm, Bombyx-Mori. Comparative Biochemistry and Physiology B-Biochemistry \& Molecular Biology 199I, 99:405-4II.

19. Ikeda M, Sasaki T, Yamashita O: Purification and Characterization of Proteases Responsible for Vitellin Degradation of the Silkworm, Bombyx-Mori. Insect Biochemistry 1990, 20:725.

20. Estrela $A$, Seixas A, Termignoni $C$ : $\mathbf{A}$ cysteine endopeptidase from tick (Rhipicephalus (Boophilus) microplus) larvae with vitellin digestion activity. Comparative Biochemistry and Physiology B-Biochemistry \& Molecular Biology 2007, I 48:4 10-4 I6

21. Medina M, Leon P, Vallejo CG: Drosophila cathepsin B-like proteinase: a suggested role in yolk degradation. Arch Biochem Biophys 1988, 263:355-363.

22. Fagotto F: Regulation of yolk degradation, or how to make sleepy lysosomes. J Cell Sci 1995, 108(Pt I2):3645-3647.

23. LeMosy EK, Kemler D, Hashimoto C: Role of Nudel protease activation in triggering dorsoventral polarization of the Drosophila embryo. Development 1998, I 25:4045-4053.

24. Bonnier P, Baert JL: Identification of Cathepsin L-Like Proteinase and Aminopeptidase in Yolk Granules of the Sand Worm, Nereis-Diversicolor. Comparative Biochemistry and Physiology B-Biochemistry \& Molecular Biology 1992, 103:425-430.

25. Cho WL, Deitsch KW, Raikhel AS: An extraovarian protein accumulated in mosquito oocytes is a carboxypeptidase activated in embryos. Proc Natl Acad Sci USA I99I, 88: 1082 I-10824.

26. Ribolla PEM, Debianchi AG: Processing of Procathepsin from Musca-Domestica Eggs. Insect Biochem Mol Biol 1995, 25:1011-1017.

27. Tadros W, Goldman AL, Babak T, Menzies F, Vardy L, Orr-Weaver T, Hughes TR, Westwood JT, Smibert CA, Lipshitz HD: SMAUG is a major regulator of maternal mRNA destabilization in Dro- sophila and its translation is activated by the PAN GU kinase. Dev Cell 2007, I 2: I43-I55.

28. De Renzis S, Elemento O, Tavazoie S, Wieschaus E: Unmasking activation of the zygotic genome using chromosomal deletions in the drosophila embryo (vol 5, art. no. ell 7, 2007). Plos Biology 2007, 5:163I-I63I.

29. Pike AW, Wadsworth SL: Sealice on Salmonids: Their Biology and Control. Adv Parasitol 1999, 44:233-337.

30. Kvamme BO, Frost $P$, Nilsen $F$ : The cloning and characterisation of full-length trypsins from the salmon louse Lepeophtheirus salmonis. Mol Biochem Parasitol 2004, 136:303-307.

31. Kvamme BO, Skern R, Frost P, Nilsen F: Molecular characterisation of five trypsin-like peptidase transcripts from the salmon louse (Lepeophtheirus salmonis) intestine. Int J Parasitol 2004, 34:823-832.

32. Kvamme $B O$, Kongshaug $H$, Nilsen $F$ : Organisation of trypsin genes in the salmon louse (Lepeophtheirus salmonis, Crustacea, copepoda) genome. Gene 2005, 352:63-74.

33. Skern-Mauritzen R, Frost P, Hamre LA, Kongshaug H, Nilsen F: Molecular characterization and classification of a clip domain containing peptidase from the ectoparasite Lepeophtheirus salmonis (Copepoda, Crustacea). Comparative Biochemistry and Physiology B-Biochemistry \& Molecular Biology 2007, I 46:289-298.

34. Emanuelsson $\mathrm{O}$, Brunak $\mathrm{S}$, von Heijne $\mathrm{G}$, Nielsen $\mathrm{H}$ : Locating proteins in the cell using TargetP, SignalP and related tools. Nat Protoc 2007, 2:953-971.

35. Hartley BS: Amino-Acid Sequence of Bovine Chymotrypsinogen-A. Nature 1964, 20I: 1284-I287.

36. Lesk AM, Fordham WD: Conservation and variability in the structures of serine proteinases of the chymotrypsin family. J Mol Biol 1996, 258:50I-537.

37. Johnson SC, Ewart KV, Osborne JA, Delage D, Ross NW, Murray HM: Molecular cloning of trypsin cDNAs and trypsin gene expression in the salmon louse Lepeophtheirus salmonis (Copepoda: Caligidae). Parasitol Res 2002, 88:789-796.

38. Eichner C, Frost P, Dysvik B, Jonassen I, Kristiansen B, Nilsen F: Salmon louse (Lepeophtheirus salmonis) transcriptomes during post molting maturation and egg production, revealed using EST-sequencing and microarray analysis. BMC Genomics 2008, 9:126.

39. Muller HM, Crampton JM, della Torre A, Sinden R, Crisanti A: Members of a trypsin gene family in Anopheles gambiae are induced in the gut by blood meal. EMBO J 1993, 12:289।-2900.

40. Ohmura K, Kohno N, Kobayashi Y, Yamagata K, Sato S, Kashiwabara $\mathrm{S}$, Baba T: A homologue of pancreatic trypsin is localized in the acrosome of mammalian sperm and is released during acrosome reaction. J Biol Chem 1999, 274:29426-29432.

41. Brunel C, Ehresmann C: Secondary structure of the 3' UTR of bicoid mRNA. Biochimie 2004, 86:91-104.

42. Lewis RA, Kress TL, Cote CA, Gautreau D, Rokop ME, Mowry KL: Conserved and clustered RNA recognition sequences are a critical feature of signals directing RNA localization in Xenopus oocytes. Mech Dev 2004, I 21:101-109.

43. Lie YS, Macdonald PM: Apontic binds the translational repressor Bruno and is implicated in regulation of oskar mRNA translation. Development 1999, I 26: I 129-I I 38.

44. Bullock SL, Zicha D, Ish-Horowicz D: The Drosophila hairy RNA localization signal modulates the kinetics of cytoplasmic mRNA transport. EMBO / 2003, 22:2484-2494.

45. Bashirullah A, Cooperstock RL, Lipshitz HD: Spatial and temporal control of RNA stability. Proc Natl Acad Sci USA 200I, 98:7025-7028.

46. Wilson CB: North American Parasitic Copepods belonging to the Family Caligidae. Part I - The Caliginae. Proceedings of the US National Museum 1905, 28:479-672.

47. McClendon JF: On the development of parasitic copepods Part II. Biol Bull I907, I 2:53-88.

48. McClendon JF: On the development of parasitic copepods Part I. Biol Bull 1906, I 2:37-52.

49. De Renzis S, Elemento O, Tavazoie S, Wieschaus EF: Unmasking activation of the zygotic genome using chromosomal deletions in the Drosophila embryo. PLoS Biol 2007, 5:el I7.

50. Ezquieta B, Vallejo CG: The Trypsin-Like Proteinase of Artemia - Yolk Localization and Developmental Activation. Compara- 
tive Biochemistry and Physiology B-Biochemistry \& Molecular Biology 1985, 82:73I-736.

51. Medina M, Vallejo CG: The Maternal Origin of Acid-Hydrolases in Drosophila and Their Relation with Yolk Degradation. Development Growth \& Differentiation 1989, 3 I:24I-247.

52. Ribolla PEM, Bijovsky AT, de Bianchi AG: Procathepsin and acid phosphatase are stored in Musca domestica yolk spheres. Journal of Insect Physiology 200I, 47:225-232.

53. Fausto AM, Gambellini G, Mazzini M, Cecchettini A, Masetti M, Giorgi F: Yolk granules are differentially acidified during embryo development in the stick insect Carausius morosus. Cell Tissue Res 2001, 305:433-443.

54. Frost $P$, Nilsen F: Validation of Reference Genes for Transcription Profiling in the Salmon Louse, Lepeophtheirus Salmonis, by Quantitative Real-Time Pcr. Veterinary Parasitology 2003, II 8:169-174.

55. Emanuelsson O, Nielsen H, Brunak S, von Heijne G: Predicting subcellular localization of proteins based on their $\mathbf{N}$-terminal amino acid sequence. J Mol Biol 2000, 300:1005-1016.

56. Bendtsen JD, Nielsen H, von Heijne G, Brunak S: Improved prediction of signal peptides: SignalP 3.0. J Mol Biol 2004, 340:783-795.

57. Krogh A, Larsson B, von Heijne G, Sonnhammer EL: Predicting transmembrane protein topology with a hidden Markov model: application to complete genomes. J Mol Biol 200I, 305:567-580.

58. Gromiha MM, Ahmad S, Suwa M: Neural network-based prediction of transmembrane beta-strand segments in outer membrane proteins. J Comput Chem 2004, 25:762-767.

59. Eisenhaber B, Bork P, Eisenhaber F: Prediction of potential GPImodification sites in proprotein sequences. J Mol Biol 1999, 292:74|-758.

60. Felsenstein J: PHYLIP (Phylogeny Inference Package) version 3.6. 2004 .

61. Strimmer K, vonHaeseler A: Quartet puzzling: A quartet maximum-likelihood method for reconstructing tree topologies. Mol Biol Evol 1996, 13:964-969.

62. Livak KJ, Schmittgen TD: Analysis of relative gene expression data using real-time quantitative PCR and the 2(-Delta Delta C(T)) Method. Methods 200I, 25:402-408.

63. Peirson SN, Butler JN, Foster RG: Experimental validation of novel and conventional approaches to quantitative real-time PCR data analysis. Nucleic Acids Res 2003, 3 I: I-7.

64. Skern R, Frost $P$, Nilsen F: Relative transcript quantification by Quantitative PCR: Roughly right or precisely wrong? Bmc Molecular Biology 2005, 6: 10. DOI 10.1 186/|47|-2199-6-10

65. Sommerset I, Skern R, Biering E, Bleie H, Fiksdal IU, Grove S, Nerland $\mathrm{AH}$ : Protection against Atlantic halibut nodavirus in turbot is induced by recombinant capsid protein vaccination but not following DNA vaccination. Fish Shellfish Immunol 2005, 18:13-29.
Publish with Bio Med Central and every scientist can read your work free of charge

"BioMed Central will be the most significant development for disseminating the results of biomedical research in our lifetime. "

Sir Paul Nurse, Cancer Research UK

Your research papers will be:

- available free of charge to the entire biomedical community

- peer reviewed and published immediately upon acceptance

- cited in PubMed and archived on PubMed Central

- yours - you keep the copyright
BioMedcentral 